\title{
DIDÁTICA DE MATEMÁTICA: SEUS PRESSUPOSTOS DE ORDEM EPISTEMOLÓGICA, METODOLÓGICA E COGNITIVA
}

\author{
DIDATICS OF MATHEMATICS: YOUR ASSUMPTIONS OF \\ EPISTEMOLPOGICAL, METHODOLOGICAL AND COGNITIVE ORDER.
}

Francisco Regis Vieira Alves $^{1}$

\begin{abstract}
Resumo
Este artigo consubstancia uma pesquisa bibliográfica centrada num interesse científico do entendimento acerca dos principais e mais representativos pressupostos de ordem epistemológica, metodológica e cognitiva atinentes ao campo de estudos nominado por Didática da Matemática - DM, relativamente à vertente francesa. Assim, com amparo numa contextualização histórica preliminar, o trabalho demarca elementos representativos que concorreram para a sistematização e acumulação de saberes científicos oriundos e teorizados a partir das interações do trinômio (professor estudante - saber matemático). Outrossim, o trabalho propugna uma série de considerações que detém o potencial de repercutir e afetar uma perspectiva distinguida para o ensino de Matemática que, de modo canônico, costuma envidar esforços apenas de modo restritivo, num componente formal e estruturalista da Matemática no locus escolar e acadêmico.
\end{abstract}

Palavras-chave: Didática da Matemática. Epistemologia. Metodologia. Ensino.

\begin{abstract}
This article constitutes a bibliographic research focused on a scientific interest in understanding the main and most representative assumptions of epistemological, methodological and cognitive studies relating to the field named for Didactics of Mathematics - DM in relation to the french branch. Thus, to support a preliminary historical context, the work marks representative elements that contributed to the systematization and accumulation of scientific knowledge and theorized coming from the triad's interactions (teacher - student - mathematical knowledge). Again, the work advocates a number of considerations that hold the potential to reverberate and affect a perspective distinguished for mathematics teaching in a canonical way, that usually efforts only and restrictively, a formal and structuralist component of mathematics in the school and academic locus.
\end{abstract}

Key-words: Didatics of Mathematics. Epistemology. Methodology. Teaching.

\footnotetext{
${ }^{1} \mathrm{O}$ autor é doutor em Educação, com ênfase no ensino de Matemática. Docente do mestrado profissional em Ensino de Ciências e Matemática- ENCIMA/UFC e coordenador do mestrado acadêmico em ensino de Ciências e Matemática PGECM/IFCE. Professor do departamento de Matemática IFCE. E-mail: fregis@ifce.edu.br
} 


\section{INTRODUÇÃO}

No final dos anos 60, registramos a efervescência intelectual, fruto da organização e a mobilização de especialistas, predominantemente atuantes no locus acadêmico, movidos e envolvidos pelo sentimento e a convicção da necessidade de profundas mudanças no sistema de ensino francês. O caso da Matemática se evidencia, pelo fato de identificarmos várias correntes, credos e percepções sobre os paradigmas canônicos seguidos na formação em Matemática, que passaram a ser revistos.

Assim, num contexto hegemônico dos fortes paradigmas do estilo e da herança bourbakista, podemos constatar um movimento questionador e forte indicativo com o intuito de rever os cânones acadêmicos adotados, até então pouco discutidos, no âmbito do ensino da Matemática, em seus vários níveis. Vale recordar que, o movimento questionador pôde ser distinguido como originado a partir de figuras humanas de diversos matizes, tais como: didatas, psicólogos, matemáticos, pedagogos, etc.

Douady $(1984$, p. 2) comenta que o matemático francês Henri Léon Lebesgue (1875 - 1941), no início do século, manifestou sérias preocupações sobre as condições de ensino e a formação do professor. Os esforços mais recentes são desenvolvidos em todo os países. Menciona ainda que reformas de programas foram decididos, decisões pedagógicas tomadas. Nesse contexto preocupante, Douady (1984) recorda que “[...] sob a impulsão de pesquisadores de horizontes diferentes: matemática, psicologia, ciências da educação, e também linguística, história, sociologia, sobretudo na França [...]" se observou forte mobilização de mudanças no campo do ensino de Matemática.

Dessa forma, a partir dos anos 80, foram criados na França, centros universitários, espalhados em todo o pais que, de modo prosaico, impulsionaram a organização e trabalho conjunto de vários profissionais, de matizes e formações variadas, realmente preocupados com melhorias no sistema de ensino. Chamados de Institutos de Pesquisa sobre o ensino de Matemática Institut Universitaire de Recherche sur L’Enseignement des Mathématiques (IREM) o que, intermédio do estabelecimento institucional e "transversal" desta estrutura de ideias possibitou, segundo Douady (1984, p. 2), a evolução de pesquisas levando em consideração os três pólos: "professor, alunos de Matemática e sistema de ensino". 
Diante do cenário acadêmico descrito nos parágrafos preliminares, com consequência de um exercício sistemático de reflexão sobre a práxis do professor e, por que não falar sobre a práxis do estudante de Matemática, apreciamos uma propugnação de teorias, cujo nascedouro foi consequência de um olhar e análise pormenorizada dos elementos envolvidos na interação professor - estudante - conhecimento matemático. Ademais, o interesse crescente pelos processos de transmissão, modificação e veiculação de saberes matemáticos culminou pela demarcação científica de uma vertente de pesquisa, com características próprias e capazes de elevar, num intervalo de duas décadas, ao alcance do status na França de área de investigação que, paulatinamente, recebeu o nome de Didática da Matemática - DM.

Isso posto, na seção subsequente, discutiremos os elementos proeminentes e determinantes de um novo campo epistêmico particular de estudos acadêmicos, interessado no ensino de Matemática, em seus variados níveis de ensino.

\section{A CONSTITUIÇÃO DE UMA ÁREA DE ESTUDOS E A INVESTIGAÇÃO CIENTÍFICA NO CAMPO DE DIDÁTICA DA MATEMÁTICA}

Como mencionamos há pouco, a constatação de uma crise no ensino de Matemática, nos anos sessenta e setenta, em redor da Matemática e em vários países, incluída a França, como acentua Douady (1995a, p. 1) impulsionou a ação de vários estudiosos. Os currículos, segundo a autora, estavam sob responsabilidade de matemáticos de renome. Tais currículos “[...] acentuavam uma aproximação matemática e davam prioridade às estruturas". Na época de predomínio de um pensamento bourbakiano $^{2}$, o objetivo pedagógico se resumia “[...] em colocar à disposição dos alunos um número reduzido de ferramentas matemáticas potentes, respeitando em todo o momento o rigor matemático". (DOUADY, 1995a, p. 2).

Douady (1995a, p. 2) acentua o papel destacado da seguinte premissa ou hipótese predominante: Os alunos teriam um número reduzido de ferramentas potentes e gerais, então, poderiam aplicá-las em situações diferentes. Por outra parte, havendo

\footnotetext{
${ }^{2}$ Corrente matemática policéfala responsável pela organização estrutural e apresentação de um novo estilo formal e algebrizante. Recordando que Kline (1967, p. 30) dizia que "o principal passo dos gregos foi em insistir o fato de que a Matemática lidava com objetos abstratos". Os membros da corrente bourbaki empregaram este ponto de vista ao extremo, com a pretensão de atingir todos os níveis de ensino.
} 
menos axiomas para enunciar, então, seria mais fácil de compreender. No excerto abaixo apreciamos a descrição, por parte de Douady, do que representaria, por décadas, um sério entrave para o ensino de Matemática.

Se introduz, então, uma série de novas noções. É o caso das relações de equivalência sobre os conjuntos. Esta noção é poderosa, posto que, se realiza um quociente de um conjunto por uma relação de equivalência, assim, se podem construir novos conjuntos com suas respectivas estruturas. Desta forma, é possível produzir, por exemplo, os negativos e os racionais, a partir dos inteiros. (DOUADY, 1995a, p. $3)$.

Ora, como consequência imediata, as concepções diretamente e indiretamente vinculadas ao excerto anterior, determinaram novas e fortes exigências na formação inicial de professores de Matemática. Ademais, os próprios hábitos e rotinas didáticas deveriam ser revistas, pelo intermédio de novos documentos oficiais pedagógicos, capazes de se fazer fortalecer um direcionamento no ensino renovado. Cabe um entendimento de que, os elementos anteriores, veementemente propugnados por figuras emblemáticas, atuantes no ensino de Matemática, a partir dos anos 30, proporcionou, até mesmo na Matemática, uma posição de isolacionismo relativamente às demais áreas de conhecimento (Física, Química, etc). Kline (1980, p, 280), comenta que muitos matemáticos abandonaram as Ciências e assumiram as trincheiras do isolacionismo.

Assim, com amparo num entendimento de um longo processo que, do ponto de vista endógeno, teve início na pesquisa matemática dos anos 30 e, passou a se tornar visível e assumiu ênfase de replicar determinados pressupostos, em todos os níveis de ensino de Matemática, um "ponto de inflexão" pôde ser detectado no final dos anos 70. Nesse sentido, Douady (1995a, p. 4) relata que:

Existia uma grande incerteza, por parte dos professores, porque os mesmos não sabiam o que deviam ensinar e tampouco sabiam que liberdade de ação se concederia ao aluno. Se encontravam bloqueados entre as várias alternativas. Se enfrentavam a exigência de rigor automático e temor de fazer afirmações que não se mostrassem corretas do ponto de vista matemático. Por outra parte, não sabiam que distância poderia tomar com o texto que dispunham. Isto gerava um esquema de ensino dogmático em que se seguia estritamente e se exigia dos alunos o que estava escrito no papel.

Fica claro, a partir do trecho anterior, a situação conflitiva de professores de Matemática que percebiam, em maior ou em menor substância, o desamparo normativo 
dos manuais em relação a determinados aspectos, nomeadamente, àqueles elementos que ultrapassam os limites da Matemática Pura. No outro elo não menos relevante do processo, isto é, no campo de ação do aluno, Douady (1995a, p. 4) assinalou conflitos também, posto que, os alunos “[...] não sabiam se respeitavam a norma e replicavam exatamente o escrito no papel, sem tentar compreender; ou se desejavam compreender, não podiam respeitar as exigências do professor. Muitos alunos vislumbravam a Matemática como algo puramente mecânico".

Diante desse quadro preocupante, as equipes multidisciplinares dos IREM's passaram a formular um trabalho diante de uma nova problemática. De modo prosaico, no que concerne à aprendizagem, se daria ênfase no significado e, por conseguinte, nos problemas de aprendizagem e de desequilíbrios para os quais os alunos não dispõem de todos os conhecimentos para a solução. Douady (1995a, p. 4) pontua que

Se produzem, então, novas perguntas. Estas perguntas são produto da reflexão fundamental de alguns investigadores em didática e são colocadas em evidência diante de uma nova gestão dos IREM's. Algumas delas, por exemplo, se referiam aos meios necessários dados aos alunos afim de permitir-lhes lograr êxito num novo equilíbrio a partir dos problemas que enfrentam, o papel do professor em um novo esquema e a criação de um saber comum na classe que seja utilizado em outras situações e que possa ser transformado num saber cultural [...].

Neste cenário de efervescência, os professores e especialistas das equipes dos IREM's decidem atuar conjuntamente nas classes com uma certa intenção de aprendizado; de realizar observações mútuas nas classes; analisar observações recorridas e tomar novas decisões. Douady (1995a, p. 5) assinala que "a Didática como campo científico entra em pleno auge". Se desenvolvem, por consequência, metodologias de investigação próprias, oriundas na tradição francesa. E, além disso, “[...] se desenvolve uma aproximação histórica e didática das Matemáticas que fornece um caráter mais humano das Matemáticas em face da necessidade de tomar em conta diferentes escalas no tempo" (DOUADY, 1995a, p. 5). Dessa forma, a constituição de uma nova vertente de investigações pode ser notada a partir das ponderações de Brousseau (1994, p. 52), quando explica o processo produtivo científico quando menciona: 


\begin{abstract}
A Didática da Matemática nasceu do interesse mobilizado nos anos 60 relativamente aos meios de melhorar o ensino de Matemática, e do orgulho de encontrar seus meios em estudos científicos apropriados. Como campo científico, ela deve acolher toda sorte de declarações e prescrições originadas de um enorme campo de disciplinas com a qual possui uma fronteira quase fractal.
\end{abstract}

Cabe observar que "[...] a didática não consiste em fornecer um modelo para o ensino, mas produzir um campo de conhecimentos e de questões que permitem colocar em prova qualquer situação de ensino e que permita corrigi-la e melhorá-la [...]" (BROUSSEAU, 1989, p. 16). Podemos depreender que a Didática da Matemática possui um terreno epistêmico intimamente condicionado pelo saber matemático. E, por intermédio de um movimento dialético, característico de sua evolução e sistematização, divisamos um corpus teórico que parte da Matemática, adquire uma robustez científica e tem capacidade de voltar a se aderir, mais uma vez, à Matemática e, todavia, “[...] não garante uma perspectiva similar aplicacionista em outros campos de saberes científicos" (MARGOLINAS, 2004, p. 4). Com efeito, “[...] a Didática da Matemática se insere num quadro das ciências cognitivas como as ciências de condições específicas na difusão dos conhecimentos matemáticos utilizados no funcionamento das instituições humanas". (BROUSSEAU, 1994, p. 53).

Aqui, buscamos indicar, de modo en passant, o contexto histórico, bem como delimitar nossa perspectiva e o conjunto de fenômenos, observáveis ou não observáveis, constituintes do campo de ação e discussão dos didátas da Matemática. No próximo segmento, restringir-nos-emos ao campo de interesse voltado para questões de gênese histórica e da natureza intrínseca dos objetos conceituais ou processo que passam a ser tomados, naturalmente, num âmbito de uma praxis direcionada para a mediação do saber matemático, segundo alguns pressupostos particulares.

\title{
PRESSUPOSTOS DE ORDEM EPISTEMOLÓGICA DA DIDÁTICA DA MATEMÁTICA
}

Podemos vislumbrar a relevância dessa perspectiva sui generis de análise e investigação dos problemas envolvendo o binômio ensino-aprendizagem, quando observamos Brousseau (1989, p. 14) ao mencionar que “[...] o matemático não 
comunica seus resultados sob a forma que eles o encontra; ele os organiza, ele os fornece uma forma mais geral possível, ele desenvolve uma 'didática prática' que consiste em colocar o saber sobre forma comunicável, descontextualizada, despersonalizada e destemporalizada". Entretanto, no âmbito do ensino, deparamos um caráter antagonista (MARGOLINAS, 1995, p. 343) ao fato indicado no excerto anterior. Com efeito, na frente do ensino, registramos um trabalho no sentido inverso, posto que o professor deverá recontextualizar e repersonalizar o saber científico, isto é, realizar uma transposição didática. (CHEVALLARD, 1991).

Contudo, diante do movimento ou um conjunto de modificações necessárias que devem ser efetivadas para que uma ação de ensino aconteça, não podemos desconsiderar a natureza intrínseca dos conteúdos, dos objetos matemáticos e dos processos matemáticos que buscamos tornar evidentes numa determinada proposta de abordagem.

Ora, o ponto de vista expresso no parágrafo anterior envolve dois elementos imprescindíveis e que requerem vigilância constante a, saber: (a) tendo em vista sua natureza crifrada, sincopada e de estilo monossêmico, a Matemática exige uma ação de modificação e transformação, levando em consideração o público de interesse; (b) a natureza dos objetos e processos matemáticos, de per si, podem proporcionar entraves e bloqueios ao ensino; (b) a natureza dos objetos e processos matemáticos, de per si, podem proporcionar entraves e bloqueios ao aprendizado dos estudantes.

Reparemos, entretanto, que em todos os itens mencionados há pouco, o fator de ordem epistemológica ou o terreno epistêmico pelo qual transitamos necessita de vigilância pois, tendo em vista sua natureza, obstáculos e entraves, muitas vezes intransponíveis, podem surgir. E, nesse contexto é que falamos de um obstáculo epistemológico.

Robinet (1983, p. 4) explica que a noção de obstáculo foi concebida, com maior sistemática no campo científico, pelo filósofo Gaston Barchelard (1884 - 1962). E, a despeito da produção de seus trabalhos em Física, Robinet comenta a adaptação das suas concepções relativamente ao conhecimento matemático. Robinet (1983, p. 4) comenta ainda que 
Barchelard demonstrou que tudo de passava como se os indivíduos estivessem submetidos, por intermédio de sua experiência sensível do real, de modelos espontâneos concernentes aos conceitos físicos. E, tais modelos espontâneos podem ser derivados do funcionamento do conhecimento produzido pelos indivíduos em resposta a determinadas questões. A força é proporcional a velocidade, por exemplo. Tais saberes correspondem, ás vezes, a uma concepção equivocada e, se colocamos o estudante à prova dessas concepções equivocadas, o estudante pode construir um conhecimento científico e corrigir seus próprios erros.

Robinet (1983, p. 5) adverte, contudo, que no ensino de Matemática, precisamos tomar certa distância. De fato, a partir da "[...] transposição brutal dos resultados de Bacherlard para a Matemática, podemos ser conduzidos para a construção de conceitos matemáticos, e colocar defeitos nas condutas espontâneas dos estudantes, adquiridas ao decurso de sua experiência". Ademais, há que se considerar a natureza intrínseca da Matemática, quando nos atemos ao contato dos estudantes com números, medida ou noções elementares de Geometria, para um nível elementar. E, num outro extremo, o contato dos estudantes com noções complexas na universidade, como sequências, processos matemáticos do Cálculo Integral e Diferencial, como conceber ideias espontâneas da realidade, tendo em vista que as mesmas condições no estudo da Física são completamente diferentes no caso dos objetos ideais e conceituais da Matemática?

Assinalamos um trecho produzido por Robinet (1983, p. 5), quando discute e compara a noção de construção histórica na Física e na Matemática.

Os especialistas na Física constroem um modelo que descreve determinada realidade, tal modelo encontra, logo em seguida um obstáculo e um novo saber deve ser construído a fim de superar tal obstáculo (a Mecânica de Newton funcionou muito bem durante um século, depois, perceberam que seus resultados não estavam mais satisfatórios para a velocidade próxima da luz e, assim, Einstein inventou a teoria da relatividade). Para a Matemática é um pouco diferente, mesmo se os matemáticos enunciam, por vezes, resultados errados, não se trata de reelaborar toda a teoria. Por exemplo, Cauchy afirmou que certa série de funções contínuas, e o resultado se mostrou falso, todavia, não houve problema na teoria a ser questionada. A demonstração do fato, corrigido pelo próprio Cauchy, tempos depois, depois do conhecimento ter sido enunciado. Ele completou a noção de convergência, acrescentando a mesma a noção de convergência uniforme. [...] nesse caso deparamos o enriquecimento de uma concepção inicialmente pobre. 
O longo excerto anterior nos permite extrair um entendimento evolutivo, de avanços e retrocessos no âmbito da construção de áreas do conhecimento distintas, não obstante, que viés pode ser destacado e quais implicações podem repercutir no ensino de Matemática?

Para responder parte do questionamento, registramos o trabalho de Robert (1988), que discute os fundamentos da DM, no final dos anos 80, quando explica que a epistemologia da Matemática adotada se evidencia por intermédio de problemas. E, “[...] de modo geral, nosso objetivo consiste em promover a aquisição de instrumentos matemáticos (conceitos) para a resolução de problemas, problemas de Matemática que conduzem (sem renunciar à aquisição que pensamos ser indissociável, dos conceitos objetos”. A inspiração na História da Matemática é flagrante, como revela Robert (1988, p. 11).

Por outro lado, uma perspectiva de análise epistemológica pode tomar também como foco um contexto social ou individual. Do ponto de vista individual, ao acentuar as ponderações de Robert (1988, p. 23), quando destaca que “[...] a aprendizagem pode ser favorizada por intermédio de um trabalho explícito sobre o tipo de representações, na medida em que, tendo em vista suas idades, os alunos são suscetíveis de perceber/distinguir entre conhecimentos e saberes sobre os conhecimentos (metaconhecimentos)". Reparemos, aqui, a ênfase no papel das representações mentais.

E, não podemos negligenciar episódios emblemáticos na História da Matemática em que o próprio sistema simbólico notacional operou no sentido de obstar ou distanciar um progresso evolutivo de significados de objetos e processos matemáticos. Dito de outra forma, a adoção de determinada representação, tendo em vista uma epistemologia que enfatiza o contexto de resolução de problemas, poderá ser mais eficiente ou menos eficientemente incorporada ao patrimônio individual e privado dos sujeitos em situação. Tal fato evidencia que a natureza intrínseca de um sistema notacional particular pode concorrer, de modo decisivo e imperativo, tanto no âmbito do ensino e da aprendizagem. Por conseguinte, uma atitude de vigilância constante do professor tornase imprescindível, afim de produzir resultados alvissareiros no campo do ensino.

Vale recordar uma perspectiva distinguida de Brousseau (1998, p. 1), ao assumir, do ponto de vista notacional, a seguinte dupla $(T, f)$ e que, o elemento 
denotado por $T$ envolve uma teoria explícita em curso de discussão, enquanto que $f$ faz referência, segundo este autor, de uma fórmula a determinar. Brousseau (1998, p. 2) questiona fortemente um modelo de ensino em que a tônica geral "consiste em delegar ao estudante para o estabelecimento de uma fórmula verdadeira, em uma teoria ao decurso do estudo". E, de modo notacional, o conteúdo de um problema pode ser resumido no par $(T, f)$. O viés hegemônico de concepções epistemológicas que consideram o par anterior, de um ponto de vista reducionista, pode ser apreciado nas seguintes ponderações:

Esta concepção permite, de modo preliminar, de colocar certos problemas relacionados com os outros, segundo a estrutura seguida, na condição de se contar com uma axiomática conveniente da teoria para ser ensinada. As discussões sobre a escolha da melhor axiomática estão subjacentes na maior parte das pesquisas sobre programas depois de vários anos. "A melhor axiomática" será àquela que permitirá com menor esforço de aprendizagem ou de ensino, afim de obter uma coleção de teoremas e problema, de exame e de controle, fixados por um consenso social. (BROUSSEAU, 1998, p. 2).

Ademais, num ambiente em que podemos presenciar a mobilização das concepções dos estudantes que, de modo predominante, superam os limites do conhecimento matemático formal, passamos a tomar a seguinte simbologia $T \mapsto f$ que, do ponto de vista de Brousseau (1998, p. 3), descreve resumidamente os conhecimentos mobilizados, tendo em vista a resolução de um problema. Nesse âmbito, vale a advertência do caráter epistemológica que reside em imprimir ao raciocínio do estudante, o caráter monossêmico e inferencial, característico das teorias formais. De modo metafórico, Caraça (1951) denomina tal função como "a economia de pensamento". Seu significado pode ser apreciado no trecho abaixo

É claro que as novas definições, uma vez que não estamos obrigados pelas antigas (que não são aplicáveis), podem ser dadas como quisermos. Mas não é menos claro que convém que essas novas definições saiam, ao menos possível, dos moldes das antigas, para que a introdução delas no cálculo se faça com o menor dispêndio de energia mental, não só no dar da definição, como nas suas consequências. (CARAÇA, 1951).

Alguns fragmentos do excerto anterior assinalam o papel importante das definições matemáticas. Assim como os teoremas e as teorias fundantes, que conferem 
seu caráter de certeza, se mostram entrelaçadas com uma "teia epistêmica" de concepções e saberes que não são negligenciados pela Didática da Matemática - DM. Não obstante, produzimos um olha restritivo, levando em consideração apenas o terreno ou a episteme do conhecimento científico (do seu lugar metodologicamente construído) de referência, e que pode, por conseguinte, estimular um expediente simplificado de apreciação. Isso posto, na seção subsequente deflagramos nosso interesse pela dimensão cognitiva ou pelos aspectos cognitivos referenciados pela DM.

\section{PRESSUPOSTOS DE ORDEM COGNITIVA DA DIDÁTICA DA MATEMÁTICA}

Brousseau (1986, p. 15) manifesta especial atenção pela aprendizagem em Matemática. Neste sentido, o autor sublinha determinados aspectos vinculados ao processo de "aprendizagem por meio de adaptações". O didata reconheceu o marco emblemático inicial demarcado por G. Piaget. Por outro lado, adverte que:

A problemática da aprendizagem por adaptação impõe a pesquisarmos, em cada atividade proposta ao aluno, que provoque nesse aluno a criação de um conhecimento visado em termos de respostas e circunstâncias. É raramente possível de se obter, de modo súbito, nestas condições, um saber correto, preciso e definido. Ao contrário, tais circunstâncias são frequentemente locais, particulares e, além disso, ligadas indevidamente, por circunstâncias escolhidas aos outros conhecimentos, ainda provisórios e incorretos. Devem, pois, evoluir, com fins a se inscrever uma gênese visando um saber cultural correto.

Brousseau (1986, p. 70) explica que uma estrutura matemática "adquire seu significado a partir da aplicação que lhe fazemos, na função que desempenha, na sua constituição com outras e, sobretudo, nos problemas que permite resolver". Assim, com base em tal perspectiva, o professor deve buscar a apresentação de um objeto matemático ou o entendimento de uma estrutura matemática, não apenas restrita à relevância e valor interno (endógeno) à própria Matemática, mas também, sua significância adquirida a partir das vivências e idiossincrasias particulares que proporciona ao aprendiz a origem de um repertório amplo de situações problema que permitam-no explorar e, paulatinamente, elabora e reelaborar construções e modelos mentais de ação eficazes. 
Brousseau (1988, p. 323) descreve o seguinte:

O ensino consiste em provocar nos alunos as aprendizagens projetadas, colocando-as em situações apropriadas às quais o aluno responde, espontaneamente, por intermédio de adaptações. Trata-se, então, de determinar quais são as adaptações que correspondem ao saber e aos conhecimentos visados, a às quais circunstâncias eles respondem.

Brousseau (1996, p. 62) explica que na concepção mais geral de ensino, “o saber é uma associação entre boas questões e boas respostas. O professor coloca um problema que o aluno deve resolver". Colocam-se, então, duas possibilidades. Se o aluno responde, o aluno demonstra que sabe. Se não, manifesta-se uma necessidade de saber e conhecer, que ele chama de informação. "A priori, todo método que permite a memorização de associações favoráveis é aceitável” (BROUSSEAU, 1996, p. 62). O contraindicado se apresenta na medida em que observamos um expediente didáticometodológico que imprime esforços exacerbados na memorização o que, para vários estudiosos, proporcionará indicativos de aprendizagem, em médio prazo, insuficientes ou frágeis, do ponto de vista da retenção.

Vale recordar, ainda, alguns princípios da maiêutica socrática que, de certa forma, limita às associações realizadas apenas pelo aluno. Tal restrição tem por objetivo “garantir a compreensão do saber por parte do aluno, pois que o mesmo produziu (BROUSSEAU, 1996, p. 62). Por outro lado, nem sempre podemos contar com um meio, conscientemente organizado, com fins de aprendizagem. Mas, a organização e controle do meio deve se mostrar razoavelmente antevisto, a ponto de que eventuais desequilíbrios cognitivos (VERGNAUD, 1981), no ato da exposição dos alunos ante a determinado assunto particular, de modo que possam ser previstos pelo professor.

Neste aspecto, Brousseau (1995, p. 62) acrescenta um ponto de vista singular, na medida em que argumenta que "o aluno aprende adaptando-se a um meio que é um fator de contradição, de dificuldades, de desequilíbrios, um pouco semelhante à sociedade humana". Um problema que levantamos diz respeito às dificuldades de concepção, criação e apresentação ao aprendiz, de um cenário de aprendizagens que encerrem contradição, que proporcionem, de modo natural, dificuldades. Ademais, que encerrem o potencial de proporcionar desequilíbrios cognitivos. 
Vale a advertência de que eventuais situações de desequilíbrio cognitivo mobilizam, de modo predominante, uma forma de raciocínio privada, tácita do estudante que, na cultura escolar ou acadêmica, costumamos nomear por intuitivo (ALVES, 2011). Assim, apesar de agir no sentido da simplificação do processo dialético de aprendizagem, podemos afirmar que, diante da resolução de uma tarefa ou situação de investigação, o estudante mobiliza dois tipos de esquemas mentais. Um deles se assenta, se mostra balizado por um corpus teórico particular, definido a priori pelo expert e, relativamente ao qual, o estudante está autorizado a desenvolver/elaborar suas inferências.

Já o segundo, a segunda forma ou categoria de esquema mental mobilizado, se assenta num significado tácito e local do estudante, recorrentemente destituído de uma justificativa explícita, todavia, se torna visível graças à ação do sujeito em situação de resolução de problemas. De modo prosaico, tal forma ou categoria de raciocínio costuma ser denominado como intuitivo. Ou, ainda, o sujeito simplesmente agiu por intuição e, por intermédio da adoção de um posicionamento pouco zeloso, nossa justificativa se encerraria por tal veredito. Assim, além de confirmarmos a difícil função do agente transmissor e responsável por uma mediação que respeite, promova e, na medida do possível, contemple algumas categorias de raciocínios mobilizáveis do aprendentes, não perdemos, também, a existência de uma multiplicidade de obstáculos, cuja natureza variada se mostra categoricamente indicada por Brousseau, logo abaixo.

Mas, no conjunto desses obstáculos cognitivos, alguns são perfeitamente evitáveis e, outros, são bastante complexos. Se alguns resultam sem recorrer ao desenvolvimento psicogenético do homem (obstáculos ontogênicos), outros são os resultados artificiais de decisões didáticas mal discutidas (obstáculos didáticos). Enquanto outros são historicamente atestados e participam de significações às quais eles se referem (obstáculos epistemológicos históricos). Dentre estes últimos, alguns são ainda atuais e não devem ser ignorados [...]. (BROUSSEAU, 1986, p. 1).

Em nossa última seção trazemos uma perspectiva de discussão resultante de dois conjuntos de elementos (de ordem epistemológica e de ordem cognitiva), imprescindíveis para a vertente de DM. Advertimos, contudo, o caráter de vanguarda da vertente francesa, pelo fato de proporcionar uma discussão sistemática e a testagem empírica de pressupostos que se encerram nesses dois conjuntos, mas não todos. Assim, 
o último conjunto de elementos ou fatores considerados residem como àqueles de ordem metodológica, que podem concorrer para uma mediação mais ou menos eficiente em sala de aula.

\section{PRESSUPOSTOS DE ORDEM METODOLÓGICA DA DIDÁTICA DA MATEMÁTICA}

Em sua tese de doutorado intitulada Théorisation des phénomènes d'enseignement de mathématiques (teorisação de fenômenos de ensino da Matemática), o didata apresenta como sua tese fundamental a seguinte afirmação:

Para produzir, melhorar, reproduzir, descrever e compreender situações de ensino da Matemática se torna necessário e possível teorizar esta atividade de ensino como um objeto original de estudo e não somente como a simples conjunção de fatos teorizados unicamente por intermédio de domínios autônomos, como Pedagogia, a Sociologia, a Psicologia, a Matemática, a Lingüística e a Epistemologia

Margolinas (2004, p. 14) explica que em uma instituição didática, a intenção de ensinar é manifestada pelos seus atores. Uma situação didática reúne estes atores em torno da intenção. Temos, todavia, dois problemas centrais pontuados por ela, a saber: (i) da relação entre saber e a origem da intenção de ensinar e a construção de uma situação didática; (ii) e da reconstrução de condições de construção de um conhecimento em situação.

Por outro lado, Brousseau esclarece ainda a possibilidade de "reprodução" no ensino de Matemática, quando acrescenta ainda que

Esta reprodutibilidade implica uma descrição, não ingênua, de todas as condições observadas, mas seletivas e que repousam sobre uma escolha pertinentes às variações possíveis de efeitos reconhecidos. A reprodutibilidade repousa, então, na compreensão dos fenômenos fundamentais, isto é, do tecido de relações atestadas, constituindo a teoria e permitindo se escolher as condições de ensino, de explicar seus efeitos e de prevê-los. (BROUSSEAU, 1986, p. 3).

Brousseau (1988, p. 313) descreve uma relação didática, habitualmente descrita de forma ternária. Ou seja, o professor, o aluno e o saber matemático. O didata fornece 
uma modelização e descrição de categorias que determinam uma situação didática. Neste sentido, Brousseau (1988, p. 316) explica que:

[...] a respeito de uma mesma noção didática, podemos visar uma família de situações onde tal noção funciona como um conhecimento (situação de ação), uma família de situações onde ela figura como um saber (por exemplo, situações de validação), uma família de situações onde identificamos uma necessidade de satisfazer, por meio da comunicação, o saber correspondente.

Ora, indubitavelmente, o conhecimento e a experiência do professor deverão concorrer para a escolha e definição de uma família gradativa de situações problema, em maior ou em menor substância vinculadas com um conceito ou vários conceitos matemáticos mais proeminentes e que, realmente, representam os elementos ensejados e perseguidos na ação didática do professor.

Robert (1998, p. 34) esclarece também a função do professor de Matemática, quando observa que:

[...] faz-se necessário sublinhar que o professor é responsável pelo contrato instalado na classe e, numa determinada margem, alterações no mesmo, que não são independentes das escolhas precedentes sobre a gestão da classe e das representações do professor sobre a Matemática e acesso ao conhecimento matemático.

Todavia, urge a escolha de um método, de uma abordagem ou estratégia sistematizada capaz de desenvolver uma perspectiva teórica que proporcione elementos, agora de ordem epistemológica, cognitiva e didática, afim de controlar, prever ou predizer o significado e a ação dos estudantes, mediante a ação intencional do professor.

Diante dessa urgência, acentuamos o papel distinguido da Teorias das Situações Didáticas - TSD, cuja robustez teórica foi atingida a partir da produção de trabalhos de da tese de Guy Brousseau, bem como pela diversidade de estudos empíricos capazes de confrontar a perspectiva teórica com os dados da realidade escolar ou acadêmica. Cabe acentuar uma noção relevante introduzida por este didata francês, nominada pelo mesmo como "modelização de situação". Em relação a tal temática, o próprio Brousseau esclarece que "[...] modelizar uma situação de ensino consiste em produzir um jogo específico sobre o conhecimento visado e o sistema de ensino [...]". (BROSSEAU, 1998, p. 316). 
Pouco mais adiante, o mesmo assinala duas funções primordiais da modelização de situações:

- No que concerne ao conhecimento, o "jogo" deve ser tal que o conhecimento aparece sob a forma escolhida ou pretendida, como a solução ou como meio de se estabelecer uma estratégia optimal. Ademais, as seguintes questões assumem papel indissociável no processo: Se o conhecimento de determinada propriedade é um meio único de passar de uma estratégia para outra? Que modificações cognitivas conduz à formulação de uma propriedade ou demonstração? A razão de produzir determinado saber é melhor, mais justa (precisa), mais eficaz do que outra?

Brousseau (1986, p. 327) justifica as questões anteriores, na medida em que esclarece "tal tipo de questões podem ser feitas a priori. Num primeiro momento, as respostas podem ser conduzidas na lógica do jogo, na História das Ciências e na análise matemática ou didática: o jogo específico de um determinado saber deve possuir um fim justificado ou sua aparição, conforme à didática teórica".

- No que concerne a atividade de ensino, o "jogo" deve permitir representar, todas as situações observadas na classe (ao menos os desenvolvimentos particulares), mesmos as menos satisfatórias assim que elas conduzam o estudante à aquisição do conhecimento visado. Ele deve deter a capacidade de promover diversas formas variantes, mesmo as mais gerais, concernentes a determinado conhecimento.

Aqui, cabe o cuidado relativamente ao qual a perspectiva de Brousseau se mostra circunscrita ao ensino elementar, com o público alvo constituído de crianças. E, dessa forma, a metáfora do "jogo" costuma ser, recorrentemente, em sua teoria, um papel de bastante atenção. Por outro lado, num contexto ampliado, diríamos o acadêmico, as concepções e análise de Brousseau exigem determinadas modificações, tendo em vista que, quando lidamos com um corpus teórico reconhecidamente complexo, determinadas ponderações de Brousseau podem ser comprovadas ineficazes.

Outrossim, a TSD contabiliza cerca de 30 anos, de tradição acadêmica, envolvendo o crivo de análise de profissionais de matizes distintos, e uma confrontação inquestionável com a realidade de ensino e institucional em vários países e, de modo particular, aqui no Brasil (ALMOULOUD, 2007). E, com arrimo de suas repercussões em vários estudos (BROUSSEAU \& CRISTOL, 2000; BROUSSEAU, 1978; 1995; 1996; 2000; DOUADY, 1984; MARGOLINAS, 1995; 1999) e dos elementos discutidos 
nas seções anteriores, acentuamos o esquema conceitual da figura 1. Nele demarcamos as linhas divisórias que circunscrevem um repertório de saberes contemplados pelo professor.

Entretanto, urge uma melhor instrumentação do professor de Matemática no que concerne aos seus pressupostos que costumam ser negligenciados (ver figura 1), na medida em que se mostre eficaz e trânsito entre os vários níveis ou saberes associados ao conhecimento matemático. Isso posto, propugnamos que uma ação didáticometodológica do professor não pode prescindir de um domínio, compreensão e o entendimento do vínculo conceitual com saberes científicos que, de modo geral, extrapolam os limites do próprio saber matemático. Com a figura 1, buscamos suscitar tal perspectiva que envolve um diagrama mnemônico dos elementos discutidos ao decurso do trabalho.

Figura 1 - Quadro conceitual indicativo dos saberes constituintes do repertório de conhecimentos e concepções acessíveis e dominadas pelo professor de Matemática

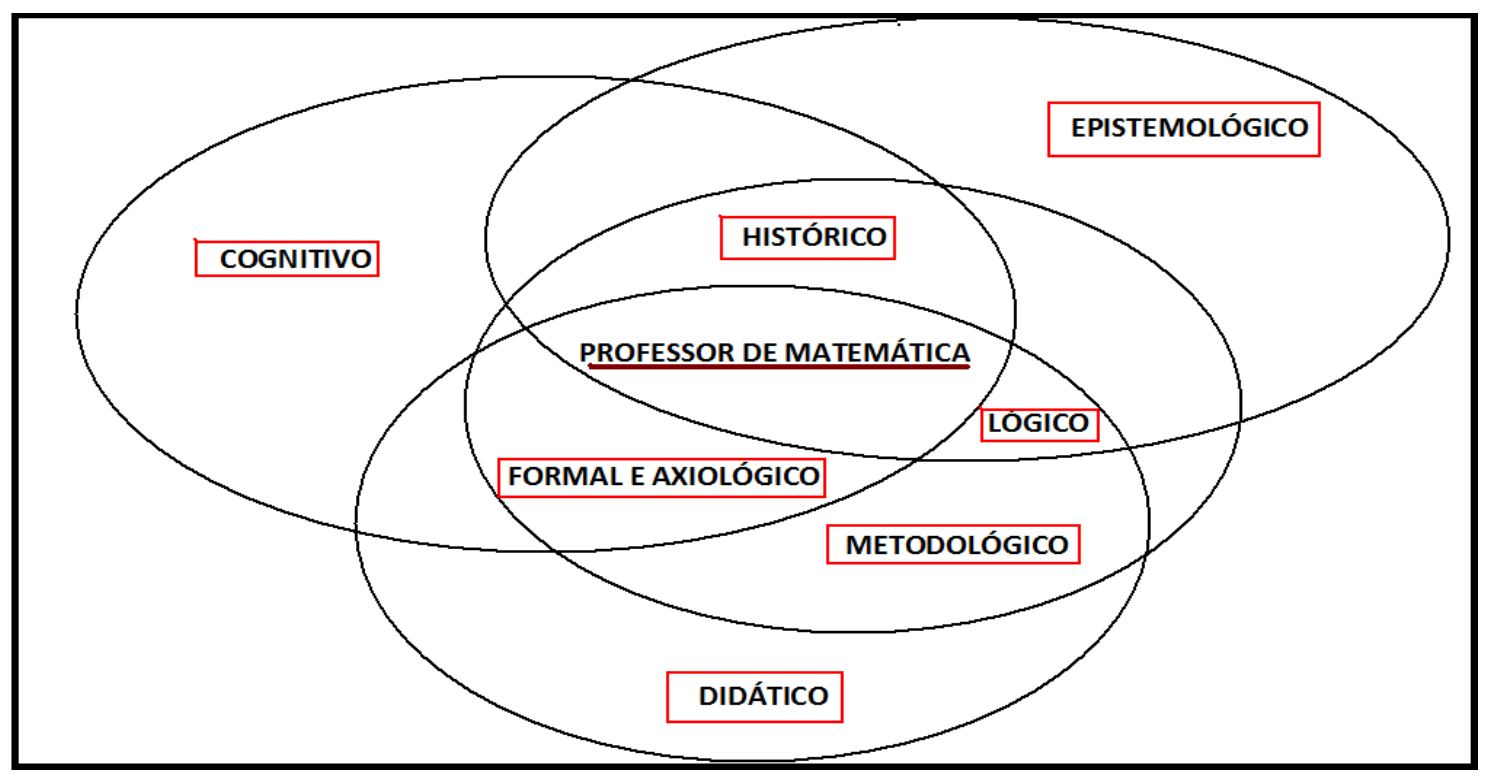

Fonte: Elaborado pelo autor.

\section{CONSIDERAÇÕES FINAIS}

Nas seções anteriores, com arrimo de uma apreciação sistemática de documentos predominantemente que discutem o papel e o processo evolutivo da DM, discutimos e 
acentuamos três dimensões que assumimos constituir um caráter de essencialidade, tendo em vista a ação do professor de Matemática. Assim, pudemos constatar a demarcação de uma esfera científica de interesses e práticas que possibilitaram um movimento progressivo de teorias (e modelos) que possibilitaram uma análise pormenorizada e apurada dos fenômenos do ensino e da aprendizagem.

Nossa opção pela vertente francesa da discussão de alguns pressupostos da DM foi determinada pelo fato histórico do pioneirismo científico, posto que, a mobilização rumo à uma constituição e demarcação desta área de estudos ocorreu primeiramente na Matemática e, ainda, tendo vem vista a robustez das teorias e modelos concebidos e produzidos pelos didatas franceses, originados e balizados por uma práxis real, imediata e concreta, envolvendo as interações entre conhecimento - estudantes - professor de Matemática.

Isso posto, a despeito de uma profusão de discursos e retóricas generalistas, que se assentam nos fenômenos didáticos (ALVES, 2012), por vezes distanciados (e esvaziados) de uma prática sistemática ou mediação concreta em sala de aula e diante de um saber científico particular (Matemática, Física, Química, etc.), a Didática da Matemática se apresenta como um corpus teórico concebido da Matemática e para Matemática, do ponto de vista das interações e dos sujeitos principais no processo (aluno e professor), cujo campo de aplicações e implicações não necessariamente se mostram factíveis em outras áreas do conhecimento. Tal característica não se evidencia como um fator de limitação ou deficiência e, sim, como um grau de especialização, aderência e um refinamento teórico, confirmado por uma prodigalidade de trabalhos e relatos profissionais, em vários países do mundo, desde o final dos anos 60 .

Por fim, apontamos alguns elementos (de ordem epistemológica, de ordem metodológica e de ordem cognitiva) de uma vertente de investigação com tradição científica, desde os anos sessenta, embora as implicações e conhecimento do professor ou o contato, familiarização e uso com tais teorias no Brasil ainda não tenham atingido um patamar amplo, satisfatório e ainda se evidenciam por ações institucionais locais e com reduzido poder de repercussão no âmbito da formação inicial e continuada de profissionais. 
Didática de matemática: seus pressupostos de ordem epistemológica, metodológica...

\section{REFERÊNCIAS}

ALMOULOUD, Ag Saddo. Fundamentos da didática da matemática. São Paulo: Editora UFPR, 2007.

ARTIGUE, Michelle. (1984). Modélisation et reproductibilité en Didáctique des Mathématiques. Les Cahier Rouge, $\mathrm{n}^{\circ}$ 8, 1 - 22.

ALVES, Francisco, R. V. Descrição e possibilidades de seu uso no ensino do Cálculo. VYDIA Educação, v. 32, nº 2, 149 - 159, 2011.

Filosofia da Matemática num curso de licenciatura: implicações para a formação do professor. Conexões, Ciência e Tecnologia, v. 6, nº 1, 44 - 66. 2012.

BROUSSEAU, G. Perspective pour la didactique des mathématiques: vingt ans de didactique des mathématiques en France. Paris: La Pensée Sauvage, 1994. p. 5 - 66.

L’observation des activités didactiques. Revue Français de Pédagogie, nº 45, 130-140, 1978.

BROUSSEAU, G. Didactiques des sciences et formation des professeurs. In : C. Comiti, T. Ngo Anh, A. Bessot, M.-P. Chichignoud \& J.-C. Guillaud (Eds.) Didactique des disciplines scientifiques et formation des enseignants. Hà Nội: Maison d'Edition de l'Education, 1995. p. 34-54.

Théorisation des phénomènes d'enseignement de mathématiques. (Thèse d'État et Sciences). Bordeaux : Université de Bordeaux I, 1986.

Les obstacles épistémologiques, problèmes et ingénierie didactique. In:

BROUSSEAU, Guy. Théorie des situations didactiques. Grenoble La Pensée Sauvage, 1998. p. 115-160.

Que peut-on enseigner en mathématiques à l'école primaire et pourquoi?

Repère IREM, v. 38, p. 7-10, 2000.

Fondement et méthode de la didactique de Mathématiques. In : BRUN, J.

Didactique des Mathématiques. Paris : Délachaux et Niestle, 45-110, 1996.

BROUSSEAU, Guy; CRISTOL, Gilles. Les études doctorales de didactique des mathématiques à l'université. Gazette des mathématiciens, v. 85, p. 55-60, 2000.

CARAÇA, Bento. de J. Conceitos Fundamentais da Matemática, Lisboa: Tipografia Matemática, 1951.

CHEVALLARD. Y. La Transposition didactique. Paris: La Pensée Sauvage Édition, 1991.

DOUADY, Régine. Didátiques des Mathematiques. Les Cahier Rouge, nº 6, p. 1 - 22, 1984. 
Nacimiento y desarrollo de la didáctica de las matemáticas en Francia. Artigue, M. Douady, R. \& Gómez, M. L. (1995). Ingeniería Didáctica en educación. 1 - 7, 1995a.

KLINE, Morris. Mathematics for the non mathemacian. New York: DOVER Publications, 1967.

Mathematics: the loss of certainty. Oxford: Oxford University, 1980.

MARGOLINAS, C. Dévolution et intitutionnalisation: deux aspects antagonistes du rôles du maître. Comiti, C.; Bessot, M. P. Didactiques des disciplines scientifiques et formation des enseignants, p. 342 - 347, 1995.

Les pratiques de l'enseignant: Une étude de didactique des mathématiques: recherche de synthèses et perspectives. Recherche en Didactiques de Mathématiques, $\mathrm{p}$. $10-33,1999$.

Points de vues de l'élève et du professeur: essai de développement de la théorie des situations didactiques (Habilitation de recherche). 2004, 160f.Provence: Université de Provence. 2004.

VERGNAUD, G. Quelques orientation théoriques eet methodoloiques des recherches française en Didactiques des Mathématiques. Recherche en Didactiques des Mathématiques, v2, n.2, p. 215 - 231, 1981. 